\title{
Survival in Idiopathic Pulmonary Fibrosis: Perspectives from Pulmonary Arterial Hypertension
}

\section{Toby M. Maher, MD; Fred Dejonckheere, MD; and Steven D. Nathan, MD}

$\mathrm{I}$ nvestigating survival in idiopathic pulmonary fibrosis (IPF) is a challenging prospect. With median survival for patients with IPF being only 2-5 years from diagnosis, ${ }^{1-3}$ the development of treatments that can improve survival is clearly of utmost importance. Unfortunately, the status of IPF as an orphan disease and the need for extended follow-up to measure survival are significant barriers to designing clinical trials powered to study mortality.,

This problem is not by any means limited to IPF. Pulmonary arterial hypertension (PAH) is another example of a rare condition, which up until the mid-1990s had no available treatment options. ${ }^{6,7}$ In the days preceding the availability of any effective treatments, mortality rates in patients with PAH were high, with 1 prospective registry across 32 clinical centers in the United States reporting a median survival of just 2.8 years. ${ }^{8}$

In the 2 decades that have passed since the results from this registry were reported, several pharmacological therapies for PAH have been developed, including prostacyclin analogs, endothelin receptor antagonists, phosphodiesterase-5 inhibitors, and a soluble guanylate cyclase stimulator. ${ }^{9}$ During the same time period, survival rates in $\mathrm{PAH}$ have undergone remarkable improvements. Before the above treatments became available, the 1-, 3-, and 5-year survival rates in $\mathrm{PAH}$ were $68 \%, 48 \%$, and $34 \%$, respectively. ${ }^{8}$ Fast forward 2 decades, and we can consider more recent registry evidence, which demonstrates reported 1-, 3-, and 5-year survival rates of 85\%-87\%, $67 \%-69 \%$, and $57 \%-61 \%$, respectively. ${ }^{10-12}$

These considerable improvements in survival could not have been predicted when these medications first came into use, largely because only very limited mortality data were available from the pivotal Phase III studies on which the approvals of these treatments were based. Mortality was not measured as an outcome in these trials, probably because the majority of these trials were less than 16 weeks in duration. ${ }^{13-16}$ The first placebo-controlled studies to include mortality as an outcome, the SERAPHIN and GRIPHON studies, were only conducted in 2013 and 2015, well after the introduction of the first wave of treatments. ${ }^{17,18}$ Surprisingly, despite the improved survival documented in the contemporary PAH population, neither of these trials found a significant effect on mortality versus placebo.

With the approval of pirfenidone and nintedanib, the IPF treatment landscape has undergone a similar transition to that observed in PAH. The situation has changed from one with few treatment options, other than best supportive care, to a situation where there are treatments with the potential to slow disease progression. Unlike in the early days of the new PAH treatments, it has already been shown that antifibrotic therapy can have a positive effect on mortality over the 1-year period evaluated in the pivotal Phase III studies. In the pooled analysis of the ASCEND and CAPACITY studies, pirfenidone significantly reduced all-cause mortality over 1 year versus placebo. ${ }^{19}$

Of course, it would be unfair to attribute increasing life expectancy in IPF to pharmacological therapy alone. There are many other factors that are likely to contribute to improved survival in patients with IPF in the future. Improvements in the accurate diagnosis of IPF are likely to have an impact on survival outcomes, particularly if diagnoses and prompt initiation of treatment can occur in the earlier stages of the disease. ${ }^{20}$ The use of standardized guidelines across regions and the phasing out of treatments that may have a detrimental effect in IPF may also play a part in improving survival. ${ }^{20-22}$

Together with these nonpharmacological aspects of clinical practice, pirfenidone and nintedanib represent an exciting advancement in care for patients with IPF. With the significant short-term survival benefits for patients with IPF already demonstrated with pirfenidone, it is interesting to consider what effects on survival might be observed if we were able to look forward 5-10 years into the future. Given that long-term survival benefits have been observed in $\mathrm{PAH}$, in the absence of any significant treatment effects in clinical trials over a period of up to 2 years, ${ }^{17,18}$ it is not unreasonable to expect median survival in IPF to begin to climb.

For those of us who would rather not wait a decade to discover the potential survival benefits of pirfenidone and nintedanib, there are statistical models that can help to predict future treatment outcomes. In fact, health technology assessments (HTAs), which are requested as part of the drug reimbursement process, use these methods. ${ }^{23}$ The indirect methods used within this supplement employ the same standardized methodology used in HTAs.

Both articles in this supplement benefit from the use of comprehensive data, collected in a systematic manner. Both articles also address the shortcomings of existing indirect evidence on long-term treatment outcomes in IPF and include a number of sensitivity analyses to support the robustness of the conclusions, as well as considerations for future analyses. Observations in $\mathrm{PAH}$ provide an interesting perspective on potential future survival benefits in IPF, and the methods and results presented within this supplement provide a systematic and robust platform on which to base predictions for long-term survival in IPF. 


\section{Authors}

TOBY M. MAHER, MD, Interstitial Lung Disease Unit, Royal Brompton Hospital/Imperial College London, London, United Kingdom; FRED DEJONCKHEERE, MD, F. Hoffmann-La Roche, Basel, Switzerland; and STEVEN D. NATHAN, MD, Advanced Lung Disease and Transplant Program, Inova Fairfax Hospital, Falls Church, Virginia.

AUTHOR CORRESPONDENCE: Toby M. Maher, MD, Interstitial Lung Disease Unit, Royal Brompton Hospital/Imperial College London, Sydney Street, Chelsea, London, SW3 6NP, United Kingdom. Tel.: +44 (0) 2073 518018; E-mail: T.Maher@rbht.nhs.uk.

\section{DISCLOSURES}

Maher has received grants, consulting fees, and speaker fees from GlaxoSmithKline and UCB and grants from Novartis. He has also received consulting fees and speaker fees from AstraZeneca, Bayer, Biogen Idec, Boehringer Ingelheim, Cipla, Lanthio, InterMune International AG (a wholly owned Roche subsidiary since 2014), F. Hoffmann-La Roche, Sanofi-Aventis, and Takeda. Maher is supported by a National Institute for Health Research Clinician Scientist Fellowship (NIHR Ref: CS:-2013-13-017). Dejonckheere is an employee of F. Hoffmann-La Roche. Nathan has received consulting fees from Roche-Genentech and Boehringer Ingelheim. He is also on the speakers bureau for Roche-Genentech and Boehringer Ingelheim and has received research funding from both companies.

All authors contributed equally to study concept and design, data collection and analysis, and manuscript preparation.

\section{ACKNOWLEDGMENTS}

Medical writing support was provided by Catherine Stanton on behalf of Complete Medical Communications and funded by F. Hoffmann-La Roche.

\section{REFERENCES}

1. Ley B, Collard HR, King TE Jr. Clinical course and prediction of survival in idiopathic pulmonary fibrosis. Am J Respir Crit Care Med. 2011;183(4):431-40.

2. Meltzer EB, Noble PW. Idiopathic pulmonary fibrosis. Orphanet J Rare Dis. 2008;3:8.

3. Strand MJ, Sprunger D, Cosgrove GP, et al. Pulmonary function and survival in idiopathic vs secondary usual interstitial pneumonia. Chest. 2014;146(3):775-85.

4. King TE Jr, Albera C, Bradford WZ, et al. All-cause mortality rate in patients with idiopathic pulmonary fibrosis. Implications for the design and execution of clinical trials. Am J Respir Crit Care Med. 2014;189(7):825-31.

5. Wells AU, Behr J, Costabel U, Cottin V, Poletti V, Richeldi L. Hot off the breath: mortality as a primary end-point in IPF treatment trials: the best is the enemy of the good. Thorax. 2012;67(11):938-40.

6. Humbert M, Sitbon O, Chaouat A, et al. Pulmonary arterial hypertension in France: results from a national registry. Am J Respir Crit Care Med. 2006;173(9):1023-30.
7. Peacock AJ, Murphy NF, McMurray JJ, Caballero L, Stewart S. An epidemiological study of pulmonary arterial hypertension. Eur Respir J. 2007;30(1):104-09.

8. D’Alonzo GE, Barst RJ, Ayres SM, et al. Survival in patients with primary pulmonary hypertension. Results from a national prospective registry. Ann Intern Med. 1991;115(5):343-49.

9. Perrin S, Chaumais MC, O'Connell C, et al. New pharmacotherapy options for pulmonary arterial hypertension. Expert Opin Pharmacother. 2015;16(14):2113-31.

10. Benza RL, Miller DP, Barst RJ, Badesch DB, Frost AE, McGoon MD. An evaluation of long-term survival from time of diagnosis in pulmonary arterial hypertension from the REVEAL Registry. Chest. 2012;142(2):448-56.

11. Humbert M, Sitbon O, Yaici A, et al. Survival in incident and prevalent cohorts of patients with pulmonary arterial hypertension. Eur Respir J. 2010;36(3):549-55.

12. Thenappan T, Shah SJ, Rich S, Tian L, Archer SL, Gomberg-Maitland M. Survival in pulmonary arterial hypertension: a reappraisal of the NIH risk stratification equation. Eur Respir J. 2010;35(5):1079-87.

13. Galiè N, Ghofrani HA, Torbicki A, et al. Sildenafil citrate therapy for pulmonary arterial hypertension. N Engl J Med. 2005;353(20):2148-57.

14. Galiè N, Rubin LJ, Hoeper M, et al. Treatment of patients with mildly symptomatic pulmonary arterial hypertension with bosentan (EARLY study): a double-blind, randomised controlled trial. Lancet. 2008;371(9630):2093-100.

15. Galiè N, Olschewski H, Oudiz RJ, et al. Ambrisentan for the treatment of pulmonary arterial hypertension: results of the ambrisentan in pulmonary arterial hypertension, randomized, double-blind, placebo-controlled, multicenter, efficacy (ARIES) study 1 and 2. Circulation. 2008;117(23):3010-19.

16. Rubin LJ, Badesch DB, Barst RJ, et al. Bosentan therapy for pulmonary arterial hypertension. N Engl J Med. 2002;346(12):896-903.

17. Pulido T, Adzerikho I, Channick RN, et al. Macitentan and morbidity and mortality in pulmonary arterial hypertension. N Engl J Med. 2013;369(9):809-18.

18. Sitbon O, Channick R, Chin KM, et al. Selexipag for the treatment of pulmonary arterial hypertension. N Engl J Med. 2015;373(26):2522-33.

19. King TE Jr, Bradford WZ, Castro-Bernardini S, et al. A phase 3 trial of pirfenidone in patients with idiopathic pulmonary fibrosis. N Engl J Med. 2014;370(22):2083-92.

20. Cottin V, Richeldi L. Neglected evidence in idiopathic pulmonary fibrosis and the importance of early diagnosis and treatment. Eur Respir Rev. 2014;23(131):106-10

21. Raghu G, Anstrom KJ, King TE Jr, Lasky JA, Martinez FJ. Prednisone, azathioprine, and N-acetylcysteine for pulmonary fibrosis. N Engl J Med. 2012;366(21):1968-77.

22. Raghu G, Rochwerg B, Zhang Y, et al. An official ATS/ERS/JRS/ALAT Clinical Practice Guideline: Treatment of Idiopathic Pulmonary Fibrosis. an update of the 2011 Clinical Practice Guideline. Am J Respir Crit Care Med. 2015;192(2):e3-19.

23. Latimer NR. Survival analysis for economic evaluations alongside clinical trials--extrapolation with patient-level data: inconsistencies, limitations, and a practical guide. Med Decis Making. 2013;33(6):743-54. 